\title{
Prevalence of Anxiety and Depression in Burns Patients in a Tertiary Care Hospital
}

\author{
Mohammed Arif ${ }^{*}$, Ramprasad K.S. ${ }^{2}$ \\ ${ }^{1}$ *(Associate Professor in General Surgery, SIMS, Shimoga/RGUHS, Karnataka State, INDIA) \\ ${ }^{2}$ (Assistant Professor in Psychiatry. SIMS, Shimoga. (RGUHS, Karnataka State, INDIA)
}

\begin{abstract}
Background and Objective: Burns injury is a major cause of anxiety and depression, contributing both as a risk factor and as an outcome process. This poses a great challenge in rehabilitation of burns patients. The main objective of this research is to understand better the frequency of anxiety and depression in burns victims and also assess the socio-demographic distribution of such cases.

Materials and Methods: 100 cases were selected among all the patients admitted to burns ward of McGann hospital Shimoga Institute of Medical sciences, during the two year period from January 2011 to December 2012, with 10\% to 50\% burns included through non-probable sampling technique. Testing protocol consisted of 21 points multiple choice questionnaire (Beck's Anxiety and Depression Inventory) including various sociodemographic variables and burn related variables. Standard statistical measures like mean with standard deviation and frequencies with proportions were calculated.

Results: Of the 100 patients, $68 \%$ were females and $32 \%$ were males. The mean age of participants was 30.12 years. Majority of victims (68\%) sustained burn injuries ranging from $25 \%-30 \%$. Accidental stove burst was the most common factor in causation in $52 \%$ cases.Anxiety was seen amongst $78 \%$ cases, out of which $30 \%$ had mild, $32 \%$ had moderate and remaining $38 \%$ had severe anxiety scores. Depression was seen in 58 patients, out of which 20 had mild, 22 had moderate and rest 14 cases had severe depression symptoms.

Conclusion:As anxiety and depression co-existed in majority of cases, it becomes highly prudent on the part of surgical team along with psychologist/psychiatrist, to simultaneously assess and manage both conditions in mild to moderate degree of burn related injuries.
\end{abstract}

Keywords:Anxiety, Depression, Burns, Beck's Inventory.

\section{Introduction}

A burn injury and itssequelae, both physical and mental are regarded as the most painful experience an affected person undergoes. The psychological and emotional aspects of burns patients are largely ignored, while care is concentrated on physiological recovery process. The different stages of adjustment and psychological challenges,a burns patient experiences are highlighted in various studies. This involves a complex interplay of patient's characteristics before injury, moderating environmental factors and the nature of injury and ensuing medical care. With this concept in mind, it is apt to assess systematically two major aspects like anxiety and depression, present either before or thereafter with proper objective evidence based scoring system. Proper rehabilitation into their social, occupational and family situation will be more easily achieved and emotional needs of the patient can be handled more effectively by this approach [1].

The main objective of this research was to determine the prevalence of anxiety and depression in burns patients, and to study their socio-demographic background and also psychological sequelae depending on nature and extent of injury.

\section{Patients And Methods}

In this study we have included 100 cases of burns patients randomly selected by non-probable purposive sampling technique, admitted to McGann hospital affiliated to Shimoga Institute of Medical Sciences, during the period of 2 years from January 2011 to December 2012.

The inclusion criteria followed were, burns of mild to moderate severity ranging from $10 \%$ to $50 \%$ in the patient category, since the time of admission to the hospital for a period of 2 weeks in the wards. The age group chosen was from 15 years to 65 years as this was thought as an understandable age for answering all the probable questions put forward to them. Written informed consent was obtained from all the patients.

Patients with co-morbid or pre-existing major psychiatric and mental disorders and relevant past history of epilepsy and mental retardation were excluded from the study group. Severe degrees of burns (more than 50\%) and burns involving the head, face and neck regions with coexistent inhalational injury and those patients who were unable to speak or gesture were also excluded from the study population. 
Data collection comprised of 21 point Beck's anxiety and Beck's Depression inventory to assess both factors simultaneously and also individually.Socio-demographic information included the age, gender, education status, marital status, occupation and geographic origin.

Statistical analysis was carried out using SPSS version II. Descriptive statistics like mean with standard deviation was calculated for age. Frequencies along with percentage were calculated for socio-demographic variables.

\section{Results and observations}

Out of 100 patients in the present study, $68 \%$ were females and rest $32 \%$ were males. The mean age of patients was 30.12 years. Statistics about socio-demographic data revealed $45 \%$ cases were under matriculation, $20 \%$ had passed matriculation and remaining $10 \%$ were Intermediate and above and $25 \%$ were illiterate. $58 \%$ were unemployed in study group mainly comprising of housewives and students. $70 \%$ of patients belonged to rural areas and 30\%fell under urban category. The detail socio-demographic profile is represented in the table 1 as follows:-

Table 1: Socio-demographic profile of patients with burns in study population.

\begin{tabular}{|c|c|}
\hline Factor & $\begin{array}{r}\text { Frequency }(\%) \\
\end{array}$ \\
\hline Age (years), mean; range & $15-65$ years range $;$ Mean $=30.12$ years \\
\hline Sex distribution & $68 \%$ females and $32 \%$ males. \\
\hline $\begin{array}{l}\text { Marital status (a)Married } \\
\begin{array}{ll}\text { (b) Widow } & \text { (c)Single/separated }\end{array}\end{array}$ & $\begin{array}{l}72 \% \\
6 \% \\
8 \% \\
\end{array}$ \\
\hline $\begin{array}{l}\text { Residence (a) Rural } \\
\text { (b) Urban }\end{array}$ & $\begin{array}{l}70 \% \\
30 \%\end{array}$ \\
\hline $\begin{array}{l}\text { Type of family (a) Nuclear } \\
\text { (b) Joint }\end{array}$ & $\begin{array}{l}26 \% \\
74 \% \\
\end{array}$ \\
\hline $\begin{array}{l}\text { Religion (a) Hindus } \\
\text { (b) Muslims }\end{array}$ & $\begin{array}{l}62 \% \\
38 \% \\
\end{array}$ \\
\hline $\begin{array}{l}\text { Education (a) Illiterate } \\
\text { (b) Up to matriculation } \\
\text { (c) Beyond matriculation } \\
\text { (d) Intermediate }\end{array}$ & $\begin{array}{l}25 \% \\
45 \% \\
20 \% \\
10 \%\end{array}$ \\
\hline $\begin{array}{lll}\text { Occupation } & \text { (a) Employed } \\
& \text { (b) Unemployed }\end{array}$ & $\begin{array}{l}42 \% \\
58 \% \\
\end{array}$ \\
\hline $\begin{array}{l}\text { Percapita income } \\
\begin{array}{ll}\text { of family } & \text { (a) } \leq 500 \\
& \text { (b) } 501-1000 \\
& \text { (c) } \geq 1000\end{array}\end{array}$ & $\begin{array}{l}32 \% \\
28 \% \\
40 \%\end{array}$ \\
\hline
\end{tabular}

Burn injury at multiple sites was seen in 54\% patients with superficial involvement of head, neck and face in $8 \%$ cases, thorax and abdomen affected in 30\% cases, legs and feet with buttocks and back in equal number $42 \%$ of cases.Majority of burns patients (68\%) had injuries extending from $25 \%$ to $35 \%$ body surface area. Accidental flame burns (stove burst or gas cylinder leakage) were the commonest cause of injury reported in $52 \%$ cases. Mild to moderate depression was seen in 44 patients while 14 cases suffered from severe depression, among the total of 58 clinically diagnosed cases of depression. Anxiety was a major co-morbid factor noticed in 78 cases, out of which $30 \%$ had mild, $32 \%$ had moderate and remaining $38 \%$ case had severe anxiety symptoms. The graphic representation of patients with anxiety alone, depression alone and both together is given in form of venn diagram below:-

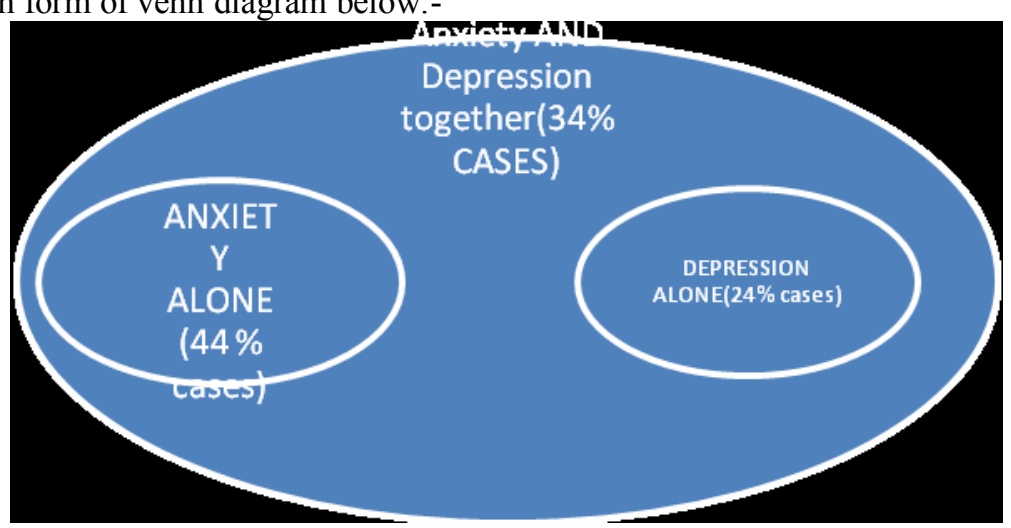




\section{Discussion}

The Beck's Depression Inventory created by Dr. Aaron .T. Beck is a 21 point multiple choice questionnaire for assessing the severity of depression. It mainly comprises of symptoms like hopelessness, irritability, cognitive thoughts of guilt, or physical symptoms of fatigue, weight loss, lack of sexual interest etc. When the test is scored, value of 0-3 is assigned for each answer. The standard cut-offs are as follows :- score 09 means patient is not depressed; score of 10-18 means mild to moderate depression; 19-29 score implies moderate to severe depression and scores of 30-63 in the scale corresponds to severe forms of depression. However the main limitation of this scoring system is that in patients with concomitant illness, physical symptoms of fatigue may aggravate the score [2].

In Beck's Anxiety Inventory, maximum score of 63 is allotted, the ranges from 0-7 meaning minimal level of anxiety, 8-15 score implies mild anxiety; 16-25 corresponding to moderate anxiety and high scores ranging from 26 to 63 , point to severe anxiety symptoms and signs. In general, womenwith anxiety disorders tend to score 4 points higher than men with anxiety[3]. Each of the items on the BAI(Beck's Anxiety Inventory) is a simple description of a symptom of anxiety in one of its four expressed aspects viz: (a) subjective (e.g. unable to relax). (b) Neurophysiologic (e.g. numbness or tingling) (c) autonomic (e.g. feeling hot) (d) panic related (e.g. fear of losing control).

In the present study, female preponderance over males was recorded which very well correlates with an Indian study where $65.7 \%$ patients were females and $34.3 \%$ were males [4].

The mean age of participants was 30.12 years in our study which favourably matched with mean age of 31.42 years in a study conducted by Tejerina. C. et al [5]

$58 \%$ of our study population were unemployed which is relatively less than study reported byAttia AF et al in Egypt recording $76 \%$ unemployment status[6]. $70 \%$ of patients in our group came from rural areas and poor socioeconomic strata of society, their monthly income being 500 to 1500 Indian rupees.

Accidental flame burns was the major causative factor in $52 \%$ of our cases as they form the common sources of fuel used in kitchen in rural areas.

Mild to moderate depression was recorded in $44 \%$ of cases and severe symptoms in $14 \%$ of cases in our study group, whereas works done by Thomas BD et al in their consecutive year series'have reported mild depression in $22 \%$ to $54 \%$, moderate depression in $13 \%$ to $26 \%$ and $18 \%$ cases with severe depression[7,8].

The observation of anxiety as seen in 78 of our subjects( $30 \%$ mild. $32 \%$ moderate, and $38 \%$ severe anxiety) correlates well with Loncar et al [9], who recorded $26 \%$ mild anxiety, $22 \%$ cases with moderate anxiety and $34 \%$ showing severe anxiety behaviour. Factors predisposing to anxiety are usually accidental circumstances leading to injury, worry about the progress of treatment and survival, fear of disfigurement and anxiety about the future rehabilitation, if disabled.

Even the total body surface area burnt was directly proportional to the level of anxiety and depression as per studies of Byers JE et al [10] and studies of PtacekJT [11]. In our study 54\% patients who sustained burns at multiple sites, especially the face and neck areas demonstrated greater levels of symptoms.

One of the other studies by Landolt MA et al [12] suggests that age, at time of burns was also related to post burn psychological adjustment. In our study, of the 68 females, 52 females (76.47\%) showed moderate to severe levels of anxiety and depression together which correlates with data published by Wiechman SA et al [13].Shelley A Wiechman has even stressed the need for supportive psychological intervention to even the immediate concerns of patient who are anxious and disturbed and who indirectly foster the same response in their patient. It becomes important to help family members understand this effect and also convey a sense of hope and calmness to the patient [13].

Female sex with facial burns were major risk factors for depression as per Van Loey NE [14].Studies carried by Von Loeyare of the view that symptoms of mood and anxiety including post-traumatic stress disorder should be the subject of screening in every post burns phase and treated actively if indicated.Studies done by Clarke MA found no significant association of educational background and unemployment status with depressive symptoms [15].

Limitations of this study are moderate number of patients involved, and no long term follow-up done in all cases and study being restricted to period of only 2 weeks of stay in the hospital. Most of our patients especially the moderate and severe varieties were not in aposition to convey or speak up their thoughts due to hypoxia/laryngeal oedema, erosive esophagitis and lastly the pain. About $20 \%$ of our patients in the study group got themselves referred to private hospitals, limiting further evaluation in detail.

\section{Conclusion}

Beck's Depression and Anxiety Inventory still hold value in evaluation of anxiety and depression in stressed individuals, who, on side are battling for physiological recovery and on the other side worried about their future in case of survival with disfigurement and deformity and also about the financial and social rehabilitation. 
Premorbid psychopathology can have adverse outcomes even in the period after injury. Medical staff should avoid treating premorbid psychopathology during the period of hospitalisation with burns. They should be tackled later on, after physical recovery.

Sleep disturbances, being the central cause of anxiety and agitation should be treated fairly along with proper pain control management with pharmacological and non -pharmacological approaches like cognitive behaviour therapy and hypnosis.

Conflicts of Interest : None.

Funding : Nil.

Ethical Clearance : Not Required

\section{Acknowledgements}

To all the suffering patients and their relatives without whom this study would not have materialised.

\section{References}

[1]. P. K. Dalal, Rahul Saha, Manu Agarwal Psychiatric aspects of burns.Indian J Plast Surg. 2010 September; 43(Suppl): S136-S142.

[2]. Moore MJ, Moore PB, Shaw PJ (October 1998). "Mood disturbances in motor neuronedisease". Journal of the neurological sciences. 160 Suppl 1: S53-6.

[3]. Beck AT, Steer RA, Ball R, Ranieri W (December 1996). "Comparison of Beck Depression Inventories -IA and -II in psychiatric outpatients". Journal of Personality Assessment67 (3): 588-97.

[4]. Lal P, Rahi M, Jain T, Ingle GK. Epidemiological study of Burn Injuries in a Slum Community of Delhi. Indian J CommunityMed 2006; 31(2):96-7.

[5]. Tejerina C, Reig A, Codina J, Safont J, Baena P, Mirabet V. Anepidemiological study of burn patients hospitalized in Valencia,Spain during 1989. Burns 1992;18(1):15-8.

[6]. Attia AF, Sherif AA, Mandil AM, Massoud MN, Abou-Nazel MW, Arafa MA. Epidemiological and sociocultural study of burn patients in Alexandria, Egypt. Eastern Mediterranean Health Journal 1997;3(3):452-61.

[7]. Thomas BD, Bresnick GM, Magyar-Russell G, Lawrence JW, McCann UD, Fauerbach JA. Depression in survivors of burn injury: A systematic review. Gen Hosp Psychiatry2006;28:494-502.

[8]. Thombs BD, Hanies JM, Bresnick MG, Magyar-Russell G,Fauerbach JA, Spence RJ. Depression in burn reconstructionpatients: symptoms prevalence and association with body imagedissatisfaction and physical function. Gen Hosp Psychiatry2007;29(1):1420 .

[9]. Loncar Z, Bras M, Mickovic V. The relationships between burn pain, anxiety and depression. CollAntropol 2006;2:319-25

[10]. Byers JF, Bridges S, Kijek J, La Borde P. Burn patients' pain andanxiety experiences. J Burn Care Rehabil 2001;22(2):144-9.

[11]. Ptacek JT, Patterson DR, Heimbach DM .Inpatient depression inpersons with burns. J Burn Care Rehabil 2002;23(1):1-9.

[12]. Landolt MA, Grubenmann S, Meuli M. Family impact greatest:Predictors of quality of life and psychological adjustment inpediatric burn survivors. J Trauma Injury Infect Critical Care2002;53:1146-51.

[13]. Wiechman SA, Ptacek JT, Patterson DR, Gibran NS, Engrav LE,Heimbach DM. Rates, Trends, and Severity of Depression afterBurn Injuries. J Burn Care Rehabil 200;22:417-24.

[14]. Van Loey NE, Van Son MJ. Psychopathology and psychological problems in patients with burn scars: epidemiology and management. Am J ClinDermatol 2003;4(4):245-72.

[15]. Clarke MA. Burns in childhood. World J Surg 1978;2:175-83. 